\title{
Preface
}

\section{Developmental Morphodynamics - bridging the gap between the genome and embryo physics}

We, the Guest Editors of this Special Issue of The International Journal of Developmental Biology, are two older embryologists, who are trying to bridge the current chasm between Entwicklungsmechanic, the developmental mechanics of our embryogenesis forefathers, and the modern movement of molecular developmental biology. Our rallying cry is that of Wilhelm His: "To think that heredity will build organic beings without mechanical means is a piece of unscientific mysticism" (His, 1888). Until recently, this claim appeared to us to fall on the somewhat deaf ears of molecular developmental biologists. Yet, the world is still one, and both physics and chemistry obviously have their place in embryogenesis. Indeed, at the molecular level, membrane proteins which are mechanoreceptors and motor molecules may begin to point the way. Here, we and our colleagues will make the case for a more equitable consideration of molecules and mechanics.

Modern developmental biology is an extremely diversified and essentially analytic science. Explorations in this field have split in many different directions and in most cases, their ultimate goal is to point to a gene, or to a set of genes "controlling" this or that process. Given the enormous recent progress in molecular techniques, such a tendency seems historically warranted and fruitful; within a short time period, we learned much about molecular processes associated with such fundamental developmental events as embryonic induction, cell differentiation, etc. However, on the other hand, our understanding of embryonic development has become more and more fragmented; percieved intuitively as a common stream, development has become separated into independent pieces, each of them requiring a specific agent, so that the task of the investigator is reduced to a simple enumeration of these agents, as if pushing a set of buttons on a key-board. The enormous gap between the genotype and phenotype, not yet bridged even in single cell morphogenesis (Gordon and Parkinson, 2005), is hardly acknowledged.

Are we doomed to accept this "button-pushing", essentially additive view as something unavoidable? Who or what is doing this pushing, or are we indeed faced with an unsatisfactory infinite regression of genes controlling genes, controlling genes...., an exasperating situation for theoretical biologists which is but dimly appreciated, or even dismissed by some molecular developmental biologists (Carroll, 2005)? Is the answer in a "dual causation of all activities of and in living organisms" (Mayr, 2004) or in emergence (Morowitz, 2002), which itself may have had to emerge (Gordon, 2000)? The question of why cells in an organism, with identical genomes, should be different from one another, has not yet been answered in any non-mystical way. Perhaps the enormous analytical progress of molecular developmental biology should stimulate us to turn towards a synthesis, that is towards formulating more or less universal "rules" of development, rather than a simple set of "instructions"? Instructions work in cooking and computing, because the cook or computer to interpret them is already present. An embryo that builds itself has no such external help. Can we make some constructive steps towards a more unified and holistic view of development, as a dynamic entity which is not reducible to a mere sum of its molecular steps?

If we turn towards the physical sciences, so much honored but little practiced by molecular biologists (whose forefathers were, after all, physicists), we can see that the tendency of recent research is directed in a holistic way ("a priori irreducible emergence", Trainor, 1997). Physics is no longer just an additive reductionist approach oriented towards an illusory goal of finding each successive specific "cause" for each natural event. The latter approach has to be relegated to the past in biology too. The clearest example of this new approach is given by what is called the theory of self-organization, or synergetics. Some attempts to apply it to developmental problems are suggested elsewhere (Beloussov, 1998). The alternation of contraction/expansion waves and changes in gene expression as a model for the genetic program may be another way of approaching the same goal (Gordon, 1999). The aim of this Special Issue of The International Journal of Developmental Biology is to arouse the interest of biologists, both those already involved in active research and those just starting their career, to the perspectives of this more holistic approach to the development of organisms which, to the minds of the Guest Editors, should be complementary, rather than opposite, to the dominating analytical approach.

Int. J. Dev. Biol. 50: 79-80 (2006)

doi: $10.1387 / \mathrm{ijdb} .052137 \mathrm{lb}$ 
The term "Morphodynamics", which we took for designating this Special Issue, symbolizes at the same time the deep historical roots of this theme and its novelty. This term was first used more than 70 years ago by an outstanding biologist Paul Weiss, one of the main proponents of a morphogenetic field theory which, after years of neglect, has recently been of increased interest (Gilbert et al., 1996). On the other hand, this term was recently reincarnated by a famous French topologist, Rene Thom and his followers for describing the, in their view universal, physical processes generating "perfectly structurized and organized macroscopic shapes from a refined (microscopic) physics of material substrates" (Petitot, 1994).

Can such an approach be fruitful today? What should be the main trends of its pursuit? The papers collected in this Special Issue should help the reader grasp the present day state-of-art of morphodynamics. The papers are quite varied in their topics and approaches. Some of them are purely theoretical and describe some refined mathematical models of morphogenetic processes. Others are essentially experimental, and a category of hybrid papers combining modeling and experimentation, and even bioengineering attempts, also is represented. Such a diversity of approaches is, in our opinion, an indication of the youth and vitality of present day Morphodynamics. Hoping that most of these approaches will fuse together in the not so distant future into more universal concepts, we think that such a process should not be artificially accelerated, and we tried to take as pluralistic and tolerant a position as possible. Two eminent scientists, representing different but complementary approaches to morphodynamics, Professors Albert Harris and Hans Meinhardt, kindly agreed to give very informal interviews to the Guest Editors of this Special Issue. We hope that their candid confessions will be of a special interest to the young readers who have to choose their own way in Science.

In general, we hope that the diverse papers collected in this Special Issue will stimulate wide and unbiased international cooperation in Morphodynamics, this really exciting and highly promising branch of developmental biology. Finally, we wish to thank the Editor-in-Chief, Professor Juan Arechaga, for his receptivity, interest and support of this enterprise and the Editorial Team of the Int. J. Dev. Biol., who have participated in an efficient manner in the mechanics of bringing this Special Issue together.

Lev V. Beloussov and Richard Gordon

Moscow, Russia and Winnipeg, Canada, November 2005

\section{References}

BELOUSSOV, L.V. (1998). The Dynamic Architecture of a Developing Organism (An Interdisciplinary Approach to the Development of Organisms). Kluwer Acad. Publ. Dordrecht-Boston-London.

CARROLL, S.B. (2005). Endless Forms Most Beautiful. The New Science of Evo Devo and the Making of the Animal Kingdom. W.W. Norton \& Co., New York, USA. GILBERT S.F., OPITZ, J.M. and RAFF, R.A. (1996). Resynthesizing evolutionary and developmental biology. Dev. Biol. 173: $357-372$.

GORDON R. (1999). The Hierarchical Genome and Differentiation Waves: Novel Unification of Development, Genetics and Evolution. World Scientific \& Imperial College Press, Singapore \& London.

GORDON, R. (2000). The emergence of emergence: a critique of "Design, observation, surprise!" Rivista di Biologia/Biology Forum 93: $349-356$.

GORDON, R. and PARKINSON, J. (2005). Potential roles for diatomists in nanotechnology. J. Nanosci. Nanotech 5: 35-40.

HIS, W. (1888). On the principles of animal morphology. Roy. Soc. Edinburgh Proc. 15: 287-298.

MAYR, E. (2004). What Makes Biology Unique? Considerations on the Autonomy of a Scientific Discipline. Cambridge University Press, Cambridge, U.K.

MOROWITZ, H.J. (2002). The Emergence of Everything. How the World Became Complex. Oxford University Press, Oxford, U.K.

PETITOT, J. (1994). Physique du sens et morphodynamique. RSSI (Recherces Semiotiques, Semiotic Inquiry) 14: 9-30.

TRAINOR, L.E.H. (1997). Emergence in physics and biology. In Physical Theory in Biology: Foundations and Explorations (Eds. Lumsden, C.J., Brandts, W.A. and

Trainor, L.E.H.). World Scientific \& Imperial College Press, Singapore, pp. 11-16.

WEISS, P.A. (1926). Morphodynamik. Abhandl. Z. Theoret. Biol. H. 23: 1-46. 